\title{
BMJ
}

\section{Risk of recurrence after venous thromboembolism in men and women: patient level meta-analysis}

\author{
James Douketis, director of vascular medicine, ${ }^{1}$ professor, ${ }^{2}$ Alberto Tosetto, medical doctor, ${ }^{3}$ Maura Marcucci, \\ medical doctor, ${ }^{4}$ Trevor Baglin, consultant haematologist, ${ }^{5}$ Benilde Cosmi, medical doctor, ${ }^{6}$ Mary Cushman, \\ professor of medicine and pathology, ${ }^{7}$ Paul Kyrle, professor, ${ }^{8}$ Daniela Poli, medical doctor, ${ }^{9}$ R Campbell Tait, \\ consultant haematologist, ${ }^{10}$ Alfonso lorio, associate professor ${ }^{11}$
}

\section{${ }^{1}$ St Joseph's Healthcare Hamilton, Room F-544, 50 Charlton Avenue East, Hamilton, ON, Canada, L8N 4A6 \\ ${ }^{2}$ Department of Medicine, McMaster University, Hamilton \\ ${ }^{3}$ Department of Hematology, San Bortolo Hospital, Vicenza, Italy \\ ${ }^{4}$ Department of Internal Medicine, Internal and Vascular Medicine, University of Perugia, Perugia, Italy}

${ }^{5}$ Department of Haematology, Addenbrooke's Hospital,

Cambridge University Hospitals N HS Trust, Cambridge, UK

${ }^{6}$ Department of Angiology and Blood Coagulation, University Hospital San Orsola-Malpighi, Bologna, Italy

${ }^{7}$ University of Vermont, Burlington, VT, USA

${ }^{8}$ Department of Medicine I, Medical University of Vienna,

Vienna, Austria

${ }^{9}$ Thrombosis Centre, Department of Heart and Vessels, University Hospital Careggi, Florence, Italy

${ }^{10}$ Department of Haematology, Royal Infirmary, Glasgow, UK

${ }^{11}$ Departments of Medicine and Clinical Epidemiology and Biostatistics, McMaster University Correspondence to: J Douketis, jdouket@mcmaster.ca

Cite this as: $B M J$ 2011;342:d813 do: $10.1136 / \mathrm{bmj} . \mathrm{d} 813$

\section{ABSTRACT}

Objective To determine the effect of sex on the risk of recurrent venous thromboembolism in all patients and in patients with venous thromboembolism that was unprovoked or provoked (by non-hormonal factors). Data source Comprehensive search of electronic databases (Medline, Embase, CINAHL, Cochrane Central Register of Controlled Trials) until July 2010, supplemented by review of conference abstracts and contact with content experts.

Study selection Seven prospective studies investigating an association between D-dimer, measured after anticoagulation was stopped, and disease recurrence in patients with venous thromboembolism.

Data extraction Patient level databases were obtained, transferred to a central database, checked, and completed with further information provided by authors. Data synthesis 2554 patients with a first venous thromboembolism had follow-up for a mean of 27.1 (SD 19.6) months. The one year incidence of recurrent venous thromboembolism was $5.3 \%$ (95\% confidence interval $4.1 \%$ to $6.7 \%$ ) in women and $9.5 \%(7.9 \%$ to $11.4 \%)$ in men, and the three year incidence of recurrence was $9.1 \%$ (7.3\% to $11.3 \%$ ) in women and $19.7 \%$ (16.5\% to $23.4 \%$ ) in men. Among patients with unprovoked venous thromboembolism, men had a higher risk of recurrence than did women (hazard ratio 2.2, 95\% confidence interval 1.7 to 2.8). After adjustment for women with hormone associated initial venous thromboembolism, the risk of recurrence remained higher in men (hazard ratio $1.8,1.4$ to 2.5 ). In patients with provoked venous thromboembolism, occurring after exposure to a major risk factor, recurrence of disease did not differ between men and women (hazard ratio 1.2, 0.6 to 2.4). In women with hormone associated venous thromboembolism and no other risk factors, recurrence was lower than that in women with unprovoked venous thromboembolism and no previous hormone use (hazard ratio $0.5,0.3$ to 0.8 ). Conclusion In patients with a first unprovoked venous thromboembolism, men have a 2.2-fold higher risk of recurrent venous thromboembolism than do women, which remained 1.8-fold higher in men after adjustment for previous hormone associated venous thromboembolism in women. In patients with a first provoked venous thromboembolism, risk of recurrence does not differ between men and women with or without hormone associated venous thromboembolism. Indefinite anticoagulation may be given greater consideration in men than in women after a first venous thromboembolism.

\section{INTRODUCTION}

Men and women are at similar risk of developing a first episode of venous thromboembolism, ${ }^{1-3}$ but men seem to have a 1.5 -fold to 2.5 -fold higher risk of recurrent venous thromboembolism after anticoagulant treatment is stopped. ${ }^{4-6}$ In all patients (men and women) with unprovoked venous thromboembolism, who comprise about a half of all patients with venous thromboembolism, ${ }^{78}$ the five year risk of recurrence is $20-30 \% .^{89}$ If the risk is truly 1.5 -fold to 2.5 -fold higher in men than in women, this may warrant consideration of indefinite (which may be lifelong) anticoagulation in men with unprovoked venous thromboembolism.

The putative association between male sex and increased risk of recurrent venous thromboembolism has not been seen in large, community based epidemiological studies, ${ }^{910}$ and it may be attributable to two potential confounders. The first is patient's age. In most studies that compared risk of recurrent disease in men and women, men were older, ${ }^{11}$ and increasing age may be a risk factor for recurrent venous thromboembolism as it is with initial disease. ${ }^{12} 13$ The second is the inclusion of women with hormone associated initial venous thromboembolism, defined as venous thromboembolism that occurs during exposure to oral contraceptive or hormone replacement therapy and no exposure to other risk factors for venous thromboembolism. As women with hormone associated venous thromboembolism are thought to have a low risk of recurrent disease, because hormonal therapy is a reversible risk factor for venous thromboembolism, ${ }^{14}$ the increased risk in men may be spurious and attributable to a lower risk in women. ${ }^{15}$ 
A study level meta-analysis found a 1.6-fold higher risk of recurrent venous thromboembolism in men than in women but could not adjust for potentially confounding variables such as patient's age and hormone associated venous thromboembolism. ${ }^{11}$ The uncertainty about the importance of sex as a risk factor for recurrent venous thromboembolism has prompted calls for further study. ${ }^{16}$ One way to overcome this uncertainty is with patient level meta-analysis, which, unlike study level meta-analysis, can adjust for potentially confounding variables. ${ }^{17}$

We did a meta-analysis of data from individual patients derived from prospective studies that included patients with a first venous thromboembolism who received standardised anticoagulant treatment, had post-anticoagulation D-dimer testing, and were followed for recurrence of disease after treatment was stopped. Our primary aim was to determine the independent effect of sex on the risk of recurrent venous thromboembolism in all patients and in patients with venous thromboembolism that was unprovoked or provoked (by non-hormonal factors). Secondarily, we aimed to determine if women with hormone associated initial venous thromboembolism were, as postulated, at lower risk for recurrence than were women who developed venous thromboembolism without previous exposure to hormonal therapy.

\section{METHODS}

A core group of investigators (JD, AT, and AI) developed the process for obtaining patient level data and the planned analyses, and all the co-authors approved them before the data collection phase. Our main objective was to develop a clinical prediction guide anchored on post-anticoagulation D-dimer status to distinguish patients' risk of recurrent venous thromboembolism, which has been published elsewhere. ${ }^{18}$ However, the richness of this database provided an opportunity to answer additional clinical questions relevant to general physicians, one of which is the focus of the study reported here.

\section{Study selection}

For selection of studies, we adopted the search strategy used for a previous study level meta-analysis, ${ }^{19}$ updating it to include more recent studies (web appendix 1). We searched major electronic databases (Medline, Embase, CINAHL, Cochrane Central Register of Controlled Trials) from their inception to July 2010.

\section{Source study characteristics}

Included studies had the following characteristics: randomised trial or prospective cohort study of patients with a first symptomatic venous thromboembolism; patients received anticoagulation with five to 10 days of heparin and at least three months of a vitamin $\mathrm{K}$ antagonist; patients had follow-up for recurrent symptomatic venous thromboembolism after anticoagulation was stopped, with outcomes objectively confirmed and independently adjudicated; and Ddimer was measured after anticoagulation was stopped. This last characteristic was not needed for the analysis reported here but was used for companion studies. ${ }^{1820}$ Patients were excluded from the source studies if they had at least one of the following when initial venous thromboembolism was diagnosed: cancer, permanent immobility, antiphospholipid antibodies, and antithrombin deficiency.

\section{Source study quality assessment}

As standardised quality criteria for meta-analyses of prognostic studies are lacking, ${ }^{21}{ }^{22}$ we used a modified Newcastle-Ottawa scale score to assesses the quality of non-randomised studies. ${ }^{23} \mathrm{We}$ evaluated the studies on the basis of the selection and outcome criteria alone, as the availability of patient level data renders selection criteria irrelevant. A study was high quality if the score was 4 or over. ${ }^{24}$ We planned to include the NewcastleOttawa scale score as a covariate in the regression analysis to evaluate its possible effect on outcome effects.

\section{Patient population}

The study population comprised patients who had all stopped anticoagulant treatment, irrespective of postanticoagulation D-dimer status. For two included studies (randomised trials) that allocated some patients with a positive $\mathrm{D}$-dimer to resume anti-coagulation, ${ }^{2526}$ we excluded such patients from our analyses. To characterise subgroups of patients pertinent to our analyses, we pre-specified the following definitions and applied them to all study populations.

Unprovoked venous thromboembolism - Venous thromboembolism that occurred in the absence of an antecedent major clinical risk factor: surgery, trauma, active cancer, immobility, or pregnancy and the puerperium. We also classified venous thromboembolism that occurred in association with hormonal therapy (oral contraceptive or hormone replacement therapy) or a thrombophilic blood abnormality and no other risk factors for venous thromboembolism as unprovoked. This was justified because hormonal therapy is considered a weak risk factor for venous thromboembolism, ${ }^{14}$ and because thrombophilic abnormalities, although they increase the risk of initial venous thromboembolism, do not seem to increase the risk of recurrent disease. $^{27}$

Provoked venous thromboembolism - Venous thromboembolism that occurred in the presence of an antecedent and transient major clinical risk factor for venous thromboembolism (as mentioned above) that occurred within three months of the initial venous thromboembolism, irrespective of exposure to concomitant hormonal therapy or the presence of a thrombophilia. We considered pregnancy associated venous thromboembolism to be provoked because the left sided predominance of lower limb venous thrombosis suggests a transient, stasis related pathogenesis. ${ }^{28} \mathrm{We}$ considered postpartum venous thromboembolism to be provoked, as it is similar in pathogenesis to surgery associated venous thromboembolism. ${ }^{14}$

Hormone associated venous thromboembolism-Venous thromboembolism that occurred in women who were 
receiving hormonal therapy (oral contraceptive or hormone replacement therapy) at the time of the initial venous thromboembolism and who had no additional risk factors. In our primary analysis, we combined oral contraception and hormone replacement therapy as a single risk factor because both types of oral hormonal therapy confer a similar twofold to fourfold increased risk for venous thromboembolism. ${ }^{2930}$ In our study, all users of hormonal therapy had received an oral contraceptive or oral hormone replacement therapy, and our findings do not pertain to users of non-oral forms of hormonal therapy.

\section{Patient follow-up and outcomes}

Follow-up started when anticoagulant treatment was stopped and ended when one of the following occurred: the patient developed recurrent venous thromboembolism with symptoms, the patient died from another cause, anticoagulation was restarted for another reason, or the study ended. No patient resumed anticoagulation during follow-up unless recurrent venous thromboembolism occurred or the patient developed another clinical indication for anticoagulant treatment.

\section{Statistical analyses}

We used Kaplan-Meier analysis to calculate the cumulative incidence of recurrent venous thromboembolism, with associated 95\% confidence intervals, at one, three, and five years after anticoagulation was stopped. We did this for all men, all women, men with unprovoked venous thromboembolism, women with unprovoked venous thromboembolism (including and excluding women with hormone associated disease), and women with hormone associated venous thromboembolism.

We calculated hazard ratios and 95\% confidence intervals for recurrent venous thromboembolism in men compared with women by using multivariable Cox regression (without and with adjustment for hormone associated initial venous thromboembolism occurring in women). We allowed for across study heterogeneity by initially running a Cox model with random effect ("shared frailty" $\gamma$ distributed) for the study variable. If we found no significant variance of $\gamma$ distribution, we used a study stratified Cox model under the fixed effect assumption. Other variables in the regression model were patient's age, cause of venous thromboembolism (unprovoked or provoked), interaction between cause of venous thromboembolism and patient's sex, and extent of deep vein thrombosis (proximal or distal). We handled patient's age as a continuous variable and an on-average centred variable calculated for each patient by subtracting the mean age of the entire study population from the patient's age.

We retained all variables if $\mathrm{P}$ was less than 0.10 or if they significantly affected the regression coefficients of other variables. We calculated hazard ratios for recurrent venous thromboembolism in men versus women with either unprovoked or provoked venous thromboembolism (we repeated these analyses after adjustment for women with hormone associated initial venous thromboembolism). We also calculated hazard ratios in women with hormone associated venous thromboembolism versus women without any antecedent risk factors. We assessed the proportional hazards assumption by analysis of Schoenfeld residuals.

\section{Sensitivity analyses}

To investigate more extensively the effect of patient's age and hormone associated initial venous thromboembolism (in women) on the risk of recurrence in men and women, coupled with our premise that these factors might be reciprocal confounders, ${ }^{11-14}{ }^{16}$ we did a post hoc sensitivity analysis with two aims: to investigate if the effect of patient's sex and hormone associated initial venous thromboembolism on risk of recurrence was age specific and to assess if use of oral contraceptive versus hormone replacement therapy during the initial venous thromboembolism had a role in determining the risk of recurrence. We achieved the first aim by adding the interaction terms between age and sex and between age and hormonal therapy in the multivariable Cox model. We inserted patient's age first as a continuous variable and also as a dichotomised variable $(\geq 60$ or $<60$ years, based on the mean and median age of the study population). We achieved the second aim by fitting only women in a multivariable Cox model with a three level variable, categorising women as oral contraceptive users, hormone replacement therapy users, or non-hormone users.

\section{RESULTS}

\section{Source study and patient characteristics}

Web appendices 1 and 2 show the derivation of the source studies used in this meta-analysis, ${ }^{252631-35}$ and table 1 describes their characteristics. Table 2 describes the characteristics of the study population of 2554 patients with a first venous thromboembolism with symptoms. The mean length of follow-up was 27.1 (SD 19.6) months, and the median length of follow-up was 22.3 (range 0.2-117.3) months. One hundred and ninety-three recurrences of venous thromboembolism occurred in men during 36046 person years of follow-up, and 97 recurrences occurred in women during 33182 person years of follow-up.

\section{Source study quality assessment}

All included studies were of high quality according to the Newcastle-Ottawa scale (table 1), and an analysis evaluating the effect of differences in study quality was not needed.

\section{Cumulative incidence of recurrent venous thromboembolism}

Table 3 shows the cumulative incidence of recurrent venous thromboembolism according to subgroups of patients defined by patient's sex and cause (unprovoked or provoked) of the initial venous thromboembolism. The one year incidence of recurrent venous 
Table 1 |Characteristics of source studies

\begin{tabular}{|c|c|c|c|c|c|}
\hline Author, year & Study design & Inclusion (exclusion) criteria & Index VTE & Monitoring for recurrent VTE & $\begin{array}{l}\text { Study quality assessment } \\
\text { according to modified NOS } \\
\text { criteria (selection/outcome)* }\end{array}$ \\
\hline Palareti, $2003^{31}$ & $\begin{array}{l}\text { Prospective cohort, } \\
\text { single centre }\end{array}$ & First VTE (excluded: lupus anticoagulant) & Leg DVT or PE & $\begin{array}{l}\text { Clinical visits } 3 \text { months after } \\
\text { stopping vitamin K antagonist, then } \\
\text { every } 6 \text { months; instructions to } \\
\text { contact if have symptoms }\end{array}$ & $4 / 3$ \\
\hline Eichinger, $2003^{32}$ & $\begin{array}{l}\text { Prospective cohort, } \\
\text { single centre }\end{array}$ & $\begin{array}{l}\text { First unprovoked VTE (excluded: surgery, trauma, or } \\
\text { pregnancy within previous } 3 \text { months; cancer; APS; } \\
\text { natural coagulation inhibitor deficiency; long term } \\
\text { anticoagulation) }\end{array}$ & Leg DVT or PE & $\begin{array}{l}\text { Clinical visits every } 3 \text { months for } \\
1 \text { year, then every } 6 \text { months }\end{array}$ & $3 / 3$ \\
\hline Palareti, $2006^{26}$ & $\begin{array}{l}\text { Randomised } \\
\text { controlled, } \\
\text { multicentre }\end{array}$ & $\begin{array}{l}\text { First unprovoked VTE (excluded: recent pregnancy or } \\
\text { puerperium, fracture or plaster casting of leg, } \\
\text { immobilisation for } \geq 3 \text { consecutive days, surgery with } \\
\text { general anaesthesia; active cancer; APS; } \\
\text { antithrombin deficiency; serious liver or renal } \\
\text { disease; other indication/contraindication for } \\
\text { anticoagulation; limited life expectancy; } \\
\text { geographical inaccessibility) }\end{array}$ & $\begin{array}{l}\text { Proximal leg DVT } \\
\text { or PE }\end{array}$ & $\begin{array}{l}\text { Clinical visits every } 3-6 \text { months; } \\
\text { instructions to contact if have } \\
\text { symptoms }\end{array}$ & $4 / 3$ \\
\hline Shrivastava, $2006^{25}$ & $\begin{array}{l}\text { Randomised } \\
\text { controlled, } \\
\text { multicentre }\end{array}$ & $\begin{array}{l}\text { Unprovoked VTE (excluded: surgery or trauma within } \\
90 \text { days of index event; APS; previous or active } \\
\text { cancer; life expectancy < } 3 \text { years) }\end{array}$ & Leg DVT or PE & Clinical visits every 2 months & $3 / 3$ \\
\hline Tait, $2007^{35}$ & $\begin{array}{l}\text { Prospective cohort, } \\
\text { multicentre }\end{array}$ & $\begin{array}{l}\text { Acute VTE in previous } 5 \text { weeks (excluded: life } \\
\text { expectancy }<3 \text { months; anticipated duration of } \\
\text { anticoagulation }>1 \text { year; unavailable for follow-up) }\end{array}$ & DVT or PE & $\begin{array}{l}\text { Nurse visit at } 3 \text { months, } 1 \text { year, and } \\
2 \text { years after stopping vitamin } \mathrm{K} \\
\text { antagonist; instructions to contact if } \\
\text { have symptoms }\end{array}$ & Not applicable \\
\hline Baglin, $2008^{34}$ & $\begin{array}{l}\text { Prospective cohort, } \\
\text { single centre }\end{array}$ & $\begin{array}{l}\text { First VTE (excluded: postoperative or pregnancy } \\
\text { associated VTE; APS; cancer; thrombosis within } \\
6 \text { weeks of surgery; other indication for prolonged } \\
\text { anticoagulation) }\end{array}$ & $\begin{array}{l}\text { Proximal leg DVT } \\
\text { or PE }\end{array}$ & Yearly follow-up & $3 / 3$ \\
\hline Poli, $2008^{33}$ & $\begin{array}{l}\text { Prospective cohort, } \\
\text { single centre }\end{array}$ & $\begin{array}{l}\text { First unprovoked VTE or VTE due to reversible risk } \\
\text { factors (excluded: APS or active cancer) }\end{array}$ & $\begin{array}{l}\text { Proximal leg DVT } \\
\text { or PE }\end{array}$ & $\begin{array}{l}\text { Follow-up twice in first year and } \\
\text { annually thereafter; instructions to } \\
\text { contact if have symptoms }\end{array}$ & $4 / 3$ \\
\hline
\end{tabular}

APS=antiphospholipid syndrome; DVT=deep vein thrombosis; $P E=$ pulmonary embolism; VTE= venous thromboembolism.

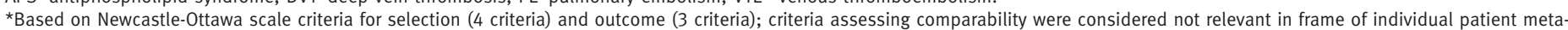
analysis.

thromboembolism was 5.3\% (95\% confidence interval $4.1 \%$ to $6.7 \%)$ in women and $9.5 \%(7.9 \%$ to $11.4 \%)$ in men; the three year incidence of recurrence was $9.1 \%$ (7.3\% to $11.3 \%)$ in women and $19.7 \%(16.5 \%$ to $23.4 \%)$ in men. Venous thromboembolism recurred less frequently in women than in men at any time during follow-up, irrespective of the subgroup studied.

\section{Risk factors for recurrent venous thromboembolism}

Table 4 shows the hazard ratios for predictors of recurrent venous thromboembolism. The log hazard ratio function was constant over time for the entire model. When we did variable by variable tests, the proportional hazard assumption was valid for all variables except for the extent of venous thrombosis variable. Including this variable in the model or excluding it from the model did not affect the other Cox regression coefficients.

Men and women with unprovoked venous thromboembolism-When we compared men and women with unprovoked venous thromboembolism (including women with hormone associated initial venous thromboembolism but no other risk factors), men had a 2.2fold higher risk of recurrent disease than did women (hazard ratio 2.2, 95\% confidence interval 1.7 to 2.8). When we repeated this comparison after adjustment for women with hormone associated venous thromboembolism, the risk of recurrence remained 1.8-fold higher in men with unprovoked venous thromboembolism than in women with unprovoked venous thromboembolism (hazard ratio $1.8,1.4$ to 2.5 ). In addition, when we adjusted for use of hormonal therapy (at the time of the initial venous thromboembolism), patient's age was no longer an independent predictor of recurrence (unadjusted hazard ratio 1.01, 1.00 to $1.02, \mathrm{P}=0.030$; adjusted hazard ratio $1.00,0.99$ to $1.01, \mathrm{P}=0.29)$.

Men and women with provoked venous thromboembolism -When we compared men and women with provoked venous thromboembolism, we found no significant difference in risk of recurrence between men and women (hazard ratio $1.2,0.6$ to 2.4 ). When we repeated this comparison after adjusting for women who had concomitant exposure to hormonal therapy, the lack of difference in risk of recurrence of venous thromboembolism between men and women persisted (hazard ratio $1.2,0.6$ to 2.3 ).

Women with or without hormone associated initial venous thromboembolism - In an analysis limited to women with venous thromboembolism who had no major risk factors before their initial venous thromboembolism, those whose disease occurred in association with hormonal therapy had a $50 \%$ lower risk of recurrence than did women without hormone associated venous thromboembolism (hazard ratio $0.5,0.3$ to 0.8 ). 
Table 2 |Characteristics of patients

\begin{tabular}{|c|c|c|c|c|c|c|c|c|c|c|c|}
\hline \multirow[b]{2}{*}{ Author, year } & \multirow[b]{2}{*}{$\begin{array}{c}\text { No of } \\
\text { patients }\end{array}$} & \multirow[b]{2}{*}{$\begin{array}{c}\text { No of men/ } \\
\text { women }\end{array}$} & \multirow[b]{2}{*}{$\begin{array}{c}\text { HT use } \\
\text { (yes/no/ } \\
\text { unknown) }\end{array}$} & \multicolumn{3}{|c|}{ Mean (SD) age (years) } & \multirow{2}{*}{$\begin{array}{c}\text { Cause of } \\
\text { initial VTE } \\
\text { (provoked/ } \\
\text { unpro- } \\
\text { voked) }\end{array}$} & \multirow{2}{*}{$\begin{array}{l}\text { Initial VTE } \\
\text { (PE or } \\
\text { proximal } \\
\text { DVT/distal } \\
\text { DVT) }\end{array}$} & \multirow{2}{*}{$\begin{array}{l}\text { Mean (SD) } \\
\text { duration of } \\
\text { anti- } \\
\text { coagulation } \\
\text { (months) }\end{array}$} & \multirow{2}{*}{$\begin{array}{l}\text { Mean (SD) } \\
\text { length of } \\
\text { follow-up } \\
\text { (months) }\end{array}$} & \multirow[b]{2}{*}{$\begin{array}{l}\text { No (\%) with } \\
\text { recurrent VTE }\end{array}$} \\
\hline & & & & All men & All women & $\begin{array}{c}\text { Women on } \\
\text { HT }\end{array}$ & & & & & \\
\hline $\begin{array}{l}\text { Palareti, } \\
2003^{31}\end{array}$ & 529 & $267 / 262$ & $40 / 489 / 0$ & $62.6(14.8)$ & $64.0(18.0)$ & $37.9(10.2)$ & $221 / 308$ & $491 / 38$ & $7.1(7.5)$ & $18.0(6.2)$ & $43(8.1)$ \\
\hline $\begin{array}{l}\text { Eichinger, } \\
2003^{32}\end{array}$ & 567 & $254 / 313$ & $164 / 403 / 0$ & $52.5(14.3)$ & $46.7(18.0)$ & $37.8(14.9)$ & $0 / 567$ & $434 / 133$ & $8.5(13.2)$ & $37.7(28.8)$ & 77 (13.6) \\
\hline $\begin{array}{l}\text { Palareti, } \\
2006^{26}\end{array}$ & 501 & $260 / 241$ & $59 / 442 / 0$ & $61.8(14.3)$ & $60.7(17.4)$ & $37.2(11.0)$ & $0 / 501$ & $501 / 0$ & $12.4(11.0)$ & $20.3(8.3)$ & $42(8.4)$ \\
\hline $\begin{array}{l}\text { Shrivastava, } \\
2006^{25}\end{array}$ & 149 & $75 / 74$ & $46 / 27 / 76$ & $54.8(12.6)$ & $52.3(12.0)$ & $51.2(11.2)$ & $1 / 148$ & $131 / 18$ & $8.3(8.4)$ & $24.5(14.7)$ & $15(10.1)$ \\
\hline Tait, $2007^{35}$ & 250 & $136 / 114$ & $32 / 218 / 0$ & $58.1(14.6)$ & $57.9(15.9)$ & $46.1(13.1)$ & $119 / 131$ & $250 / 0$ & $6.0(1.0)$ & $20.6(11.3)$ & $27(10.8)$ \\
\hline Baglin, $2008^{34}$ & 271 & $142 / 129$ & $19 / 252 / 0$ & $60.5(17.5)$ & $65.3(18.6)$ & $43.6(16.1)$ & $74 / 197$ & $271 / 0$ & $6.3(0.9)$ & $37.7(16.5)$ & 49 (18.1) \\
\hline Poli, $2008^{33}$ & 287 & $152 / 135$ & $30 / 256 / 1$ & $58.6(15.0)$ & $60.3(17.4)$ & 43.9 (14.1) & $110 / 177$ & $287 / 0$ & $13.3(11.0)$ & $31.7(21.7)$ & $37(12.9)$ \\
\hline Pooled & 2554 & $1286 / 1268$ & $\begin{array}{c}390 / 2087 / \\
77\end{array}$ & $58.8(15.2)$ & $57.6(18.7)$ & $40.7(14.1)$ & $525 / 2029$ & $2365 / 189$ & $8.9(8.7)$ & 27.1 (19.6) & $290(11.4)$ \\
\hline
\end{tabular}

DVT=deep vein thrombosis; $\mathrm{HT}=$ hormonal therapy; $\mathrm{PE}=$ pulmonary embolism; VTE=venous thromboembolism.

\section{Sensitivity analyses}

Interaction between age, sex, and hormone associated initial venous thromboembolism - The interaction between age and sex suggested that age was a predictor in women only (hazard ratio $1.02,1.01$ to 1.03 ), but adjustment for hormonal therapy in a model with only women almost completely explained the effect of age (hazard ratio $1.01,0.99$ to 1.02 ).

Effect of hormone type (oral contraceptive, hormone replacement therapy) in women with hormone associated initial venous thromboembolism on risk of recurrence-Of 390 women with hormone associated initial venous thromboembolism, the type of hormonal therapy used was specified in only 65 women $(17 \%, 27$ oral contraceptive users, 38 hormone replacement therapy users), so we reclassified all women by using a threshold of the value midway between the medians of age in women on oral contraceptive or hormone replacement therapy (47 years). Multivariable Cox modelling in only women showed that compared with non-hormone users who developed venous thromboembolism, oral contraceptive associated initial venous thromboembolism was associated with a lower risk of recurrence (hazard ratio $0.39,0.16$ to 0.91 ); women with hormone replacement therapy associated initial venous thromboembolism also had a lower risk of recurrence, although this was not statistically significant (hazard ratio $0.76,0.39$ to 1.49 ). These findings were independent of the effect of age.

\section{DISCUSSION}

This analysis of more than 2500 patients with a first venous thromboembolism who were followed, on average, for 2.5 years after stopping anticoagulation has three main findings. Firstly, among patients with unprovoked venous thromboembolism men had a 2.2-fold higher risk of recurrence of disease than did women. After adjustment for women with initial hormone associated venous thromboembolism, a potential major confounder, the risk of recurrence remained 1.8-fold higher in men than in women. Secondly, in patients with provoked venous thromboembolism the risk of recurrent disease did not differ between men and women. Thirdly, in women with hormone associated initial venous thromboembolism the risk of recurrence was $50 \%$ lower than in women without hormone associated initial venous thromboembolism.

\section{Possible explanations of findings}

Several hypotheses have been proposed to explain the association between male sex and increased risk of recurrent venous thromboembolism as one that is spurious. Firstly, the increased risk of recurrence in men is purportedly due to their more advanced age at the time of diagnosis compared with women. ${ }^{11}$ In our study, patient's age was comparable in men and women (mean age 58.8 v 57.6 years) and statistical adjustment for age did not affect our findings. Secondly, sex specific differences in length of treatment or post-treatment follow-up might account for differences in rates of recurrence of disease. In our study, men received longer anticoagulation than did women (mean 13.0 (SD 11.0) v9.0 (10.1) months), but the duration of anticoagulation does not seem to affect the risk of recurrent venous thromboembolism. ${ }^{3637}$ Men had a comparable length of follow-up to women (mean 25.8 (SD 18.5) v 28.4 (20.5) months).

Thirdly, men might be more likely to have diagnostic testing for recurrent venous thromboembolism than women, as with coronary artery disease,${ }^{38}$ and might thus be more likely to be diagnosed as having a recurrence. Although we could not compare the threshold for diagnostic testing for recurrent venous thromboembolism in men and women, no evidence exists to suggest that such testing occurs less in women. Previous studies have found a higher prevalence of confirmed deep vein thrombosis in men than in women 
Table 3 |Cumulative incidence of recurrent venous thromboembolism (VTE) in all patients according to sex and hormonal therapy status

Cumulative incidence of recurrent VTE: events per patient year of follow-up $(95 \% \mathrm{Cl})$

\begin{tabular}{|c|c|c|c|c|c|}
\hline \multirow[b]{2}{*}{$\begin{array}{l}\text { Time after anticoagulation } \\
\text { stopped }\end{array}$} & \\
\hline & All men & All women & $\begin{array}{l}\text { Men with } \\
\text { unprovoked VTE }\end{array}$ & $\begin{array}{l}\text { Women with unprovoked VTE (including } \\
\text { women with previous hormone } \\
\text { associated VTE) }\end{array}$ & $\begin{array}{l}\text { Women with unprovoked VTE (excluding } \\
\text { women with previous hormone } \\
\text { associated VTE) }\end{array}$ \\
\hline 1 year & 9.5 (7.9 to 11.4$)$ & 5.3 (4.1 to 6.7 ) & 10.4 (8.6 to 12.8$)$ & 5.6 (4.3 to 7.3$)$ & 6.7 (4.9 to 9.2 ) \\
\hline 2 years & 14.1 (11.9 to 16.6$)$ & 7.9 (6.4 to 9.8$)$ & $15.8(13.2$ to 18.8$)$ & 8.3 (6.6 to 10.5$)$ & 10.6 (8.1 to 13.8$)$ \\
\hline 3 years & 19.7 (16.5 to 23.4$)$ & 9.1 (7.3 to 11.3$)$ & 22.5 (18.8 to 27.0$)$ & 9.1 (7.2 to 11.6$)$ & $10.6(8.1$ to 13.8$)$ \\
\hline 5 years & 36.3 (28.7 to 45.9$)$ & 11.1 (8.6 to 14.4 ) & 43.1 (33.8 to 55.1$)$ & 11.5 (8.7 to 15.2$)$ & $12.2(9.3$ to 16.2$)$ \\
\hline
\end{tabular}

with suspected thrombosis, ${ }^{39-41}$ suggesting that women either are more likely to seek medical attention for suspected thrombosis or prompt a lower threshold for diagnostic testing. Fourthly, men may have more extensive venous thromboembolism than women, which may lead to more recurrence. ${ }^{18}$ This is also unlikely, as the extent of disease seems to be similar in men and women. ${ }^{42}$ Fifthly, men might have a higher incidence of occult cancer, which would lead to more recurrent venous thromboembolism. Although our included studies did not document the development of cancer during follow-up and excluded patients with cancer at the time of their initial venous thromboembolism, this explanation is unlikely as a difference in incidence of cancer in men and women with venous thromboembolism has not been found..$^{43-46}$

Sixthly, men may have a higher incidence of the metabolic syndrome or other cardiovascular risk factors, which seem to confer an increased risk of venous thromboembolism. ${ }^{47-49}$ If such factors are more common in men and contribute to the development of recurrent venous thromboembolism, one would also expect a higher incidence of first venous thromboembolism in men, which has not been seen. ${ }^{1-3}$ Although these associations are plausible, further study is needed. ${ }^{5051}$ Seventhly, men may be more likely to be exposed to high risk situations, such as surgery, than women and may develop more provoked recurrent venous thromboembolism. However, a sex specific predilection to risk factors for venous thromboembolism, apart from use of hormonal therapy and pregnancy, seems unlikely. Although we were unable to assess this in our database, a study assessing whether men had more provoked recurrent venous thromboembolism events than women found that men had more unprovoked recurrent events, which supports our premise. ${ }^{52}$ Finally, the observed risk differential in men and women may be due to a lower baseline risk of recurrence in women. This is purportedly attributed to the fact that women develop hormone associated initial venous thromboembolism, which confers a lower risk of disease recurrence. ${ }^{53}$ Although this explanation is plausible, it only partially accounts for the sex specific difference in risk for recurrence.

In patients with provoked venous thromboembolism, which occurred after exposure to a major risk factor such as surgery, patient's sex was not associated with risk of recurrence. Although this finding may seem to refute our conclusion of a sex specific effect on recurrence, the interpretation of findings in this subgroup of patients is limited because the number of patients studied was smaller and patients with provoked venous thromboembolism have a low risk of recurrence. ${ }^{54}$ Furthermore, the confidence interval around the risk estimate for recurrence in patients with provoked venous thromboembolism did not exclude a twofold higher risk in men than women. The mechanism for sex specific recurrence may be unique to patients with unprovoked venous thromboembolism. Also, women with hormone associated initial venous thromboembolism have a 50\% lower risk of recurrence than do comparable women who develop venous thromboembolism in the absence of any antecedent risks. This suggests that hormone associated initial venous thromboembolism, particularly for oral contraceptive associated disease, has a clinical course that is more comparable to that of provoked venous thromboembolism than unprovoked disease. In another study assessing risk of recurrence after hormone associated initial venous thromboembolism, although the risk of recurrence did not seem to be lower in women with oral contraceptive associated venous thromboembolism (hazard ratio $0.6,95 \%$ confidence interval 0.1 to 2.8 ) or hormone replacement therapy associated disease $(1.8,0.6$ to 5.2$)$ who stopped hormonal therapy, the findings should be interpreted with caution because of wide confidence limits around the risk estimates. ${ }^{55}$

\section{Strengths and limitations of study}

The strength of our study is that it represents, to our knowledge, the largest prospectively derived data source comparing the risk of recurrent venous thromboembolism in men and women. When juxtaposed against a study level meta-analysis of 5416 patients in which recurrent venous thromboembolism was compared in men and women, ${ }^{11}$ the findings for risk of recurrence after unprovoked venous thromboembolism were similar in this study (relative risk 1.5, 1.1 to $1.9)$ and our study $(1.8,1.4$ to 2.5$)$. However, in patients with provoked venous thromboembolism, whereas the study level meta-analysis reported a higher risk of recurrence in men than in women (relative risk 1.5, 1.1 to 2.1 ), our findings differed (1.2, 0.6 to 2.4). Such comparisons, however, need cautious interpretation given differences in analytical methods. In individual studies assessing patients with treated venous thromboembolism, the risk of recurrent disease was higher in men than in women in most, ${ }^{5656-62}$ but not all, ${ }^{863}$ studies. 
Table 4 Predictors of recurrent venous thromboembolism (VTE) in multivariable Cox regression analysis

\section{Groups of patients for comparison}

Risk of recurrent VTE-

Initial VTE unprovoked†:

\begin{tabular}{ll}
\hline Men $v$ all women $\ddagger$ & 2.2 (1.7 to 2.8) \\
\hline Men $v$ women (excluding women with previous hormone associated VTE)§ & 1.8 (1.4 to 2.5) \\
\hline $\begin{array}{l}\text { Women with previous hormone associated VTE } v \text { women without previous } \\
\text { hormone associated VTE and no other antecedent risk factors }\end{array}$ & 0.5 (0.3 to 0.8)
\end{tabular}

hormone associated VTE and no other antecedent risk factors

Initial VTE provokedT:

Men $v$ all women

$1.2(0.6$ to 2.4$)$

Men $v$ women (excluding women with previous hormone associated VTE)§

$1.2(0.6$ to 2.3$)$

*All estimates came from study stratified Cox regression model with fixed effect (as no significant variance of $y$ distribution for "shared frailty" was seen).

†VTE occurring in absence of major antecedent risk (for example, surgery, trauma).

fHazard ratio from model including age, unprovoked/provoked VTE, interaction between unprovoked/provoked and sex, and proximal/distal VTE as covariates.

§Hazard ratio from model including use/non-use of hormonal therapy, age, unprovoked/provoked VTE,

interaction between unprovoked/provoked VTE and sex, and proximal/distal VTE as covariates.

TVTE occurring in presence of antecedent transient major risk.

We acknowledge potential limitations. Firstly, our findings are limited to the studies included in this meta-analysis. Although this may imply a study selection bias, we pre-specified the study selection criteria, thus minimising such bias. The advantage gained with a patient level meta-analysis was in having a large sample of original data and the ability to adjust for potential confounders. ${ }^{11}$ Secondly, unmeasured determinants may explain the differential risk of recurrence of venous thromboembolism in men and women, and additional research is needed to explain our findings. Thirdly, including patients with hormonal therapy associated initial venous thromboembolism as unprovoked disease may be questioned. We made this decision a priori, and the fact that hormonal therapy is considered to be a weak risk factor for venous thromboembolism compared with major risk factors such as surgery justifies this. ${ }^{16}$ Furthermore, a standard definition of unprovoked venous thromboembolism is lacking; some studies have included hormone associated venous thromboembolism as unprovoked, ${ }^{4266364}$ whereas others have not. ${ }^{3665}$ None the less, we prespecified analyses that would adjust for these subgroups of patients when assessing risk of recurrence in men and women. Finally, our findings are based

\section{WHAT IS ALREADY KNOWN ON THIS TOPIC}

Whether men have a higher risk of recurrent venous thromboembolism than do women is uncertain, partly because previous studies did not control for potential sources of bias

If men are at higher risk of recurrence, this would mean that men may need a longer duration of anticoagulant treatment than do women

\section{WHAT THIS STUDY ADDS}

After unprovoked venous thromboembolism, the risk of recurrence is 2.2 -fold higher in men than in women; this remained 1.8-fold higher after adjustment for women who had hormone associated disease

After provoked venous thromboembolism, the risk of recurrence is similar in men and women

Indefinite anticoagulation may be given greater consideration in men than in women after a first venous thromboembolism on a predominantly white population and may not be applicable to other racial groups, in whom further research is needed to assess prognosis of venous thromboembolism. ${ }^{66}$

\section{Implications of findings}

Our findings suggest that in patients with a first unprovoked venous thromboembolism, patient's sex may be an important consideration in deciding about the need for long term anticoagulant treatment. Ideally, a clinical prediction guide that incorporates objective clinical, imaging (residual thrombosis on venous ultrasonography), and laboratory (post-anticoagulation D-dimer) factors to predict recurrence should be sought. ${ }^{67}$ One clinical prediction rule seemed to be useful in women but not men with unprovoked venous thromboembolism. ${ }^{5}$ Additional studies to look at this are planned. ${ }^{68}$ Our finding that women with hormone associated venous thromboembolism have a lower risk of recurrence than do women with venous thromboembolism that occurs in the absence of any antecedent risks may reassure clinicians and patients of a good prognosis after hormone associated disease, assuming discontinuation of hormonal therapy. Overall, our findings are relevant to the considerable number of patients worldwide, estimated to be 200000 in North America alone, who are diagnosed each year as having a first episode of venous thromboembolism. ${ }^{36970}$

\section{Conclusions}

In patients with a first unprovoked venous thromboembolism, men have a 2.2 -fold higher risk of recurrent venous thromboembolism than do women. This risk remained 1.8-fold higher in men than women after adjustment for women who had hormone associated venous thromboembolism. In patients with a first provoked venous thromboembolism, we found no difference in risk of recurrence between men and women.

We thank Clive Kearon and Shannon Bates for their review of this manuscript. The authors reported the following sources of funding for the studies included in this meta-analysis: FCSA (Federazione dei Centri di Sorveglianza e Monitoraggio della Terapie Antitrombotiche)cit_bcit_af ref_bf(Palareti, 2003 ref_num4924 / Palareti, 2006 \#4925)ref_af; Oesterreichische Nationalbank (Jubilaeumsfonds), the MedizinischWissenschaftlicher Fonds des Buergermeisters der Bundeshauptstadt Wien, and the Wiener Staedtische Versicherungcit_cit_af ref_bf (Eichinger, 2003 ref_num4923)ref_af; Chief Scientist Office, Scottish Executive Health Department (grant CZB/4/24)cit_cit_af ref_bf(Tait, 2007 ref_num4934)ref_af; HL-57951 and HL-58036 from the US National Heart, Lung, and Blood Institute.

Contributors: JD, Al, MM, and AT planned the study, developed the analysis plan, interpreted the study findings, and prepared and critically reviewed the manuscript. TB, BC, MC, PK, DP, and RCT provided the individual patient databases, interpreted the study findings, and critically reviewed the manuscript. JD and Al are the guarantors.

Funding: None

Competing interests: All authors have completed the Unified Competing Interest form at www.icmje.org/coi_disclosure.pdf (available on request from the corresponding author) and declare: no support from any organisation for the submitted work; no financial relationships with any organisations that might have an interest in the submitted work in the previous three years, no other relationships or activities that could appear to have influenced the submitted work.

Ethical approval: Not needed.

Data sharing: No additional data available. 
1 White RH, Zhou H, Murin S, Harvey D. Effect of ethnicity and gender on the incidence of venous thromboembolism in a diverse population in California in 1996. Thromb Haemost 2005;93:298-305.

2 Heit JA. The epidemiology of venous thromboembolism in the community: implications for prevention and management. J Thromb Thrombolysis 2006;23:21-9.

3 Spencer FA, Emery C, Joffe SW, Pacifico L, Lessard D, Reed G, et al. Incidence rates, clinical profile, and outcomes of patients with venous thromboembolism: the Worcester Venous Thromboembolism Study. J Thromb Thrombolysis 2009;28:401-9.

4 Kyrle PA, Minar E, Bialonczyk C, Hirschl M, Weltermann A, Eichinger S. The risk of recurrent venous thromboembolism in men and women. $N$ Engl J Med 2004;350:2558-63.

5 Rodger MA, Kahn SR, Wells PS, Anderson DA, Chagnon I, Le Gal G, et al. Identifying unprovoked thromboembolism patients at low risk for recurrence who can discontinue anticoagulant therapy. CMAJ 2008;179:417-26.

6 Baglin T, Luddington R, Brown K, Baglin C. Incidence of recurrent venous thromboembolism in relation to clinical and thrombophilic risk factors: prospective cohort study. Lancet 2003;362:523-6.

7 Spencer FA, Gore JM, Reed G, Lessard D, Pacifico L, Emery C, et al. Venous thromboembolism and bleeding in a community setting: the Worcester Venous Thromboembolism Study. Thromb Haemost 2009;101:878-85.

8 Prandoni P, Noventa F, Ghirarduzzi A, Pengo V, Bernardi E, Pesavento R, et al. The risk of recurrent venous thromboembolism after discontinuing anticoagulation in patients with acute proximal deep vein thrombosis or pulmonary embolism: a prospective cohort study in 1626 patients. Haematologica 2007;92:199-205.

9 Hansson PO, Sorbo J, Eriksson H. Recurrent venous thromboembolism after deep vein thrombosis: incidence and risk factors. Arch Intern Med 2000;160:769-74.

10 Heit JA, Mohr DN, Silverstein MD, Petterson TM, O’Fallon WM Melton LJ. Predictors of recurrence after deep vein thrombosis and pulmonary embolism: a population-based cohort study. Arch Intern Med 2000;160:761-8.

11 McRae S, Tran H, Schulman S, Ginsberg J, Kearon C. Effect of patient's sex on risk of recurrent venous thromboembolism: a meta-analysis. Lancet 2006;368:371-8.

12 Gjores JE. The incidence of venous thrombosis and its sequelae in certain districts in Sweden. Acta Chir Scand 1993;111(suppl 206):16-24S

13 Gillum RF. Pulmonary embolism and thrombophlebitis in the United States, 1970-1985. Am Heart / 1987;114:1262-4.

14 Anderson FA, Spencer FA. Risk factors for venous thromboembolism. Circulation 2003;107(suppl 1):19-16S.

15 Lijfering WM, Veeger NJ, Middeldorp S, Hamulyák K, Prins MH, Bülle $\mathrm{HR}$, et al. A lower risk of recurrent venous thrombosis in women compared with men is explained by sex-specific risk factors at time of first venous thrombosis in thrombophilic families. Blood 2009;114:2031-6.

16 Pengo V, Prandoni P. Sex and anticoagulation in patients with idiopathic venous thromboembolism. Lancet 2006;368:342-3.

17 Sud S, Douketis J. The devil is in the details ... or not? A primer on individual patient data meta-analysis. Ann Intern Med 2009;151:JC1-3.

18 Tosetto A, lorio A, Marcucci M, Baglin T, Cushman M, Eichinger S, et al. Clinical prediction guide to predict thrombosis recurrence after a first unprovoked venous thromboembolism. J Thromb Haemost 2009;7(suppl 2):OC-TH-004S.

19 Verhovsek M, Douketis JD, Yi Q, Shrivastava S, Tait RC, Baglin T, et al. Systematic review: D-dimer to predict recurrent disease after stopping anticoagulant therapy for unprovoked venous thromboembolism. Ann Intern Med 2008;149:481-90.

20 Douketis JD, Tosetto A, Marcucci M, Baglin T, Cushman M, Eichinger S, et al. Patient-level meta-analysis: effect of measurement timing, threshold, and patient age on ability of D-dimer testing to assess risk for recurrence after unprovoked venous thromboembolism. Ann Intern Med 2010;153:523-31.

21 Merlin T, Weston A, Tooher R. Extending an evidence hierarchy to include topics other than treatment: revising the Australian levels of evidence. BMC Med Res Methodol 2009;9:34

22 Altman DG. Systematic review of evaluations of prognostic variables. BMJ 2001;323:224-8.

23 Wells G, Shea B, O'Connell D, Peterson J, Welch V. Losos M, et al. The Newcastle-Ottawa scale (NOS) for assessing the quality of nonrandomized studies in meta-analyses. 2011. www.ohri.ca/ programs/clinical epidemiology/oxford.htm.

24 Millet GA, Flores SA, Marks G, Reed JB, Herbst JH. Circumcision status and risk of HIV and sexually transmitted infections among men who have sex with men. JAMA 2008;300:1674-84.

25 Shrivastava S, Ridker PM, Glynn RJ, Goldhaber SZ, Moll S, Bounameaux H, et al. D-dimer, factor VIII coagulant activity, low- intensity warfarin and the risk of recurrent venous thromboembolism. J Thromb Haemost 2006;4:1208-14.

26 Palareti G, Cosmi B, Legnani C, Tosetto A, Brusi C, lorio A, et al. D dimer testing to determine the duration of anticoagulation therapy. $N$ Engl J Med 2006;355:1780-9.

27 Agnelli G, Becattini C. Treatment of DVT: how long is enough and how do you predict recurrence? J Thromb Thrombolys 2008;25:37-44

28 Chan WS, Lee A, Spencer FA, Crowther M, Rodger M, Ramsay T, et al. Predicting deep venous thrombosis in pregnancy: out in "LEFt" field? Ann Intern Med 2009;151:85-92.

29 Douketis JD, Ginsberg JS, Holbrook A, Crowther M, Duku EK, Burrows RF. A reevaluation of the risk for venous thromboembolism with the use of oral contraceptives and hormone replacement therapy. Arch Intern Med 1997;157:1522-30.

30 Canonico M, Plu-Bureau G, Lowe GD, Scarabin PY. Hormone replacement therapy and risk of venous thromboembolism in postmenopausal women: systematic review and meta-analysis. $B M$ 2008;336:1227-31.

31 Palareti G, Legnani C, Cosmi B, Valdre L, Lunghi B, Bernardi F, et al. Predictive value of $D$-dimer test for recurrent venous thromboembolism after anticoagulation withdrawal in subjects with previous idiopathic event and in carriers of congenital thrombophilia. Circulation 2003;108:313-8.

32 Eichinger S, Minar E, Bialonczyk C, Hirschl M, Quehenberger P, Schneider B, et al. D-dimer levels and risk of recurrent venous thromboembolism. JAMA 2003;290:1071-4.

33 Poli D, Antonucci E, Ciuti G, Abbate R, Prisco D. Combination of D dimer, $\mathrm{F} 1+2$ and residual vein obstruction as predictors of VTE recurrence in patients with first VTE episode after OAT withdrawal. Thromb Haemost 2008;6:708-10.

34 Baglin T, Palmer CR, Luddington R, Baglin C. Unprovoked recurrent venous thrombosis: prediction by D-dimer and clinical risk factors. Thromb Haemost 2008;6:577-82.

35 Tait R, Lowe GDO, McColl MD, McMahon AD, Robertson L, King L, et al. Predicting risk of recurrent venous thrombosis using a 5-point scoring system including fibrin D-dimer. J Thromb Haemost 2007;5(suppl 2):0-M-060S

36 Agnelli G, Prandoni P, Santamaria MG, Bagatella P, Iorio A, Bazzan M, et al, for the Warfarin Optimal Duration Italian Trial Investigators. Three months versus one year of oral anticoagulant therapy for idiopathic deep venous thrombosis, N Engl / Med 2001;345:165-9.

37 Agnelli G, Prandoni P, Becattini C, Silingardi M, Taliani MR, Miccio M, et al. Extended oral anticoagulant therapy after a first episode of pulmonary embolism. Ann Intern Med 2003;139:19-25.

38 Chang AM, Mumma B, Sease KL, Robey JL, Shofer FS, Hollander JE. Gender bias in cardiovascular testing persists after adjustment for presenting characteristics and cardiac risk. Acad Emerg Med 2007;14:599-605.

39 Kahn SR, Joseph L, Abenhaim L, Leclerc JR. Clinical prediction of deep vein thrombosis in patients with leg symptoms. Thromb Haemost 1999;81:353-7.

40 Oudega R, Moons KG, Hoes AW. Limited value of patient history and physical examination in diagnosing deep vein thrombosis in primary care. Fam Pract 2005;22:86-91.

41 Beebe HG, Scissons RP, Salles-Cunha SX, Dosick SM, Whalen RC, Gale SS, et al. Gender bias in use of venous ultrasonography for diagnosis of deep venous thrombosis. I Vasc Surg 1995;22:538-42.

42 Andreou RE, Koru-Sengul T, Linkins L, Bates SM, Ginsberg JS. Differences in clinical presentation of deep vein thrombosis in men and women. J Thromb Haemost 2008;6:1713-9.

43 Douketis JD, Gu C, Piccioli A, Ghirarduzzi A, Pengo V, Prandoni P. The long-term risk of cancer in patients with a first episode of venous thromboembolism. J Thromb Haemost 2009;7:546-51.

44 Schulman S, Lindmarker P. Incidence of cancer after prophylaxis with warfarin against recurrent venous thromboembolism: Duration of Anticoagulation Trial. N Engl J Med 2000;342:1953-8.

45 Baron JA, Gridley G, Weiderpass E, Nyren G, Linet M. Venous thromboembolism and cancer. Lancet 1998;351:1077-80.

46 Sorensen HT, Mellemkjaer L, Olsen JH, Nielsen GL. The risk of a diagnosis of cancer after primary deep-venous thrombosis or pulmonary embolism. N Engl J Med 1998;338:1169-73.

47 Ageno W, Becattini C, Brighton T, Selby R, Kamphuisen PW. Cardiovascular risk factors and venous thromboembolism: a metaanalysis. Circulation 2008;117:93-102.

48 Steffen LM, Cushman M, Peacock JM, Heckbert SR, Jacobs DR Jr, Rosamond WD, et al. Metabolic syndrome and risk of venous thromboembolism: Longitudinal Investigation of Thromboembolism Etiology (LITE). J Thromb Haemost 2009;7:746-51.

49 Borch KH, Braekken SK, Mathiesen EB, Njolstad I, Wilsgaard T, Stormer J, et al. Abdominal obesity is essential for the risk of venous thromboembolism in the metabolic syndrome: the Tromso Study. J Thromb Haemost 2009; 7:739-45.

50 Prandoni P. Venous thromboembolism and atherosclerosis: is there a link? J Thromb Haemost 2007;5(suppl 1):270-5S. 
51 Ageno W, Dentali F, Grandi AM. New evidence on the potential role of the metabolic syndrome as a risk factor for venous thromboembolism. / Thromb Haemost 2009;7:736-8.

52 Christiansen SC, Lijfering WM, Helmerhorst FM, Rosendaal FR, Cannegieter SC. Sex difference in risk of recurrent venous thrombosis and the risk profile for a second event. J Thromb Haemost 2010;8:2159-68.

53 Cushman M, Glynn RJ, Goldhaber SZ, Moll S, Bauer KA, Deitcher S, et al. Hormonal factors and risk of recurrent venous thrombosis: the Prevention of Recurrent Venous Thromboembolism Trial. J Thromb Haemost 2006;4:2199-203.

54 Kearon C, Ginsberg JS, Anderson DR, Kovacs MJ, Wells P, Julian JA, et al. Comparison of 1 month with 3 months of anticoagulation for a first episode of venous thromboembolism associated with a transient risk factor. J Thromb Haemost 2004;2:743-9.

55 Le Gal G, Kovacs MJ, Carrier M, Do K, Kahn SR, Wells PS, et al. Risk of recurrent venous thromboembolism after a first oestrogenassociated episode: data from the REVERSE Cohort Study. Thromb Haemost 2010;104:498-503.

56 Kearon C, Kahn SR, Agnelli G, Goldhaber S, Raskob GE, Comerota AJ. Antithrombotic therapy for venous thromboembolic disease: American College of Chest Physicians evidence-based clinical practice guidelines (8th edition). Chest 2008;133(suppl 6):454-545S.

57 Levine MN, Hirsh J, Gent M, Turpie AG, Weitz J, Ginsberg J, et al. Optimal duration of oral anticoagulant therapy: a randomized trial comparing four weeks with three months of warfarin in patients with proximal deep vein thrombosis. Thromb Haemost 1995;74:606-11.

58 Schulman S, Rhedin AS, Lindmarker P, Carlsson A, Lärfars G, Nicol P, et al. A comparison of six weeks with six months of oral anticoagulant therapy after a first episode of venous thromboembolism. N Engl J Med 1995;332:1661-5.

59 Schulman S, Granqvist S, Holmstrom M, Carlsson A, Lindmarker P, Nicol $P$, et al. The duration of oral anticoagulant therapy after a second episode of venous thromboembolism. N Engl J Med 1997;336:393-8.

60 Piovella F, Crippa L, Barone M, Vignanò D’Angelo S, Serafini S, Galli L et al. Normalization rates of compression ultrasonography in patients with a first episode of deep vein thrombosis of the lower limbs: association with recurrence and new thrombosis. Haematologica 2002;87:515-22.

61 Agnelli G, Becattini C, Prandoni P. Recurrent venous thromboembolism in men and women. $N$ Engl J Med 2004;351:2015-8.

62 Franzeck UK, Schalch I, Jager KA, Schneider E, Grimm J, Bollinger A. Prospective 12-year follow-up study of clinical and hemodynamic sequelae after deep vein thrombosis in low-risk patients (Zurich Study). Circulation 1996;93:74-9.

63 Kearon C, Gent M, Hirsh J, Weitz J, Kovacs MJ, Anderson DR, et al. A comparison of three months of anticoagulation with extended anticoagulation for a first episode of idiopathic venous thromboembolism. N Engl J Med 1999;340:901-7.

64 Oger E, Lacault K, Le Gal G, Couturaud F, Guénet D, Abalain JH, et al. Hyperhomocysteinemia and low vitamin B levels are independently associated with venous thromboembolism: results from the EDITH Study: a hospital-based case-control study. J Thromb Haemost 2006:4:793-9.

65 Piccioli A, Lensing AWA, Prins MH, Falanga A, Scannapieco GL, leran $\mathrm{M}$, et al, for the SOMIT Investigator Group. Extensive screening for occult malignant disease in idiopathic venous thromboembolism: a prospective randomized clinical trial. J Thromb Haemost 2004;2:884-9.

66 White RH, Keenan CR. Effects of race and ethnicity on the incidence of venous thromboembolism. Thromb Res 2009;123(suppl 4):11-7S.

67 Eichinger S, Kyrle PA. Duration of anticoagulation after initial idiopathic venous thrombosis-the swinging pendulum: risk assessment to predict recurrence. J Thromb Haemost 2009;7(suppl 1):291-5S

68 ClinicalTrials.gov. Clinical decision rule validation study to predict low recurrent risk in patients with unprovoked venous thromboembolism (REVERSEII). 2011. www.clinicaltrials.gov/ct2/ show/NCT00967304.

69 White RH. Epidemiology of venous thromboembolism. Circulation 2003;107(suppl 1):14-8S

70 Heit JA. Venous thromboembolism: disease burden, outcomes and risk factors. J Thromb Haemost 2005;3:1611-7.

Accepted: 21 December 2010 